\title{
Interactive comment on "Effect of Atmospheric Stability on the Wind Resource extrapolating models for large capacity Wind Turbines: A Comparative Analysis of Power Law, Log Law and Deaves and Harris mode" by Pramod Kumar Sharma et al.
}

Anonymous Referee \#3

Received and published: 22 May 2018

Section 2. Commendable effort but this is mainly textbook material not relevant to a published paper.

Section 3. Jamgodrani hills have a huge potential in terms of power production. Table wind resource as huge. You can check http://rredc.nrel.gov/wind/pubs/atlas/tables/11T.html for a mre systematic nomenclature of wind resource. Also, consider adjusting 
the one-year measuremennt to the long-term so that the statements are more accurate and less depednent on your short-term observations.

WESD

Section 4. I cannot see any original contribution. The content is limited to reporting WinPro graphs.

Section 5. Conclusions are limited to the studied case. Not sure of their value at large.

Interactive Aldo, the study is incomplete with respect to current wind engineering standard. More complete analyses are performed daily by wind analysts across the globe for wind project development.

Interactive comment on Wind Energ. Sci. Discuss., https://doi.org/10.5194/wes-2018-16, 2018. 